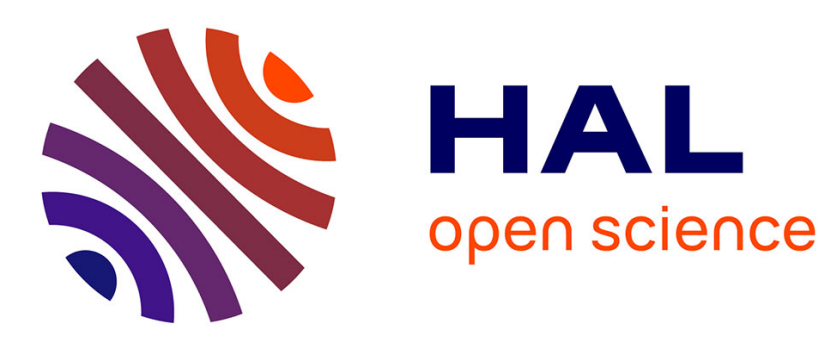

\title{
Magnetic susceptibility and viscosity of soils in a weak time varying field
}

Michel Dabas, Alain Jolivet, Alain Tabbagh

\section{To cite this version:}

Michel Dabas, Alain Jolivet, Alain Tabbagh. Magnetic susceptibility and viscosity of soils in a weak time varying field. Geophysical Journal International, 1992, 108 (1), pp.101-109. 10.1111/j.1365246X.1992.tb00841.x . hal-02926437

\section{HAL Id: hal-02926437 https://hal.science/hal-02926437}

Submitted on 31 Aug 2020

HAL is a multi-disciplinary open access archive for the deposit and dissemination of scientific research documents, whether they are published or not. The documents may come from teaching and research institutions in France or abroad, or from public or private research centers.
L'archive ouverte pluridisciplinaire HAL, est destinée au dépôt et à la diffusion de documents scientifiques de niveau recherche, publiés ou non, émanant des établissements d'enseignement et de recherche français ou étrangers, des laboratoires publics ou privés. 


\title{
Magnetic susceptibility and viscosity of soils in a weak time varying field
}

\author{
Michel Dabas, Alain Jolivet and Alain Tabbagh \\ Centre de Recherches Géophysiques, CNRS, Garchy 58150, France
}

Accepted 1991 June 3. Received 1991 March 15; in original form 1990 September 19

\begin{abstract}
SUMMARY
We try in this paper to characterize the magnetic behaviour of soils both in the frequency and time domain. Our aim is to understand the anomalous responses we have observed in many EM surveys.

A wide range of soil samples have been analysed with two instruments specially designed for harmonic $(80 \mathrm{~Hz}-10 \mathrm{kHz})$ and transient $(8-100 \mu$ s after cut-off) $\mathrm{EM}$ low inducing fields $(50 \mu \mathrm{T})$.

The most common spectrum observed could be explained with the well-dispersed single-domain grain theory (SD): a logarithmic decrease of the in-phase susceptibility with frequency and a constant quadrature susceptibility. Moreover, measurements in the frequency domain of the quadrature susceptibility and measurements of the coefficient of viscosity in the time domain have been compared and found to be in good accordance with theory. But other types of magnetic spectrum were encountered and could not be accounted for SD theories. This results in a non-logarithmic dependence of the in-phase susceptibility, a non-constant quadrature susceptibility and in the time domain a coefficient of viscosity $S$ which is time dependent.

It is demonstrated that the response due to quadrature magnetic susceptibility in the frequency domain and the magnetic viscosity in the time domain is sufficiently strong to be responsible for the anomalous responses.

It is now possible to correct in an EM survey for the soil magnetic effect for a better determination of resistivity or conductivity.
\end{abstract}

Key words: EM prospecting, magnetic susceptibility, magnetic viscosity, soil, viscous remanent magnetization.

\section{INTRODUCTION}

Measurement of electrical conductivity of soils by classical EM prospecting methods encounters the problem of a magnetic response originating in the ordinary soil's magnetic susceptibility (Buselli 1982; Tabbagh 1986). This occurs either in the frequency domain, or in the time domain (TDEM). Using the classical Slingram method with phase separation of the EM components, we have obtained on numerous sites anomalous conductivities within high magnetic areas (Dabas 1989). In the past, this phenomenon was hidden partly because of the search for very conductive targets as in mining prospecting, partly because of qualitative interpretations. But we must take it into account when considering precise measurements and/or poorly conductive targets.

The aim of this paper is to highlight the origin of this phenomenon by characterizing in practice and theoretically the magnetic response of soils. A forthcoming paper will explain the in-field corrections proposed.

Soil magnetic properties are usually different from their parent rock. This fact was established more than 30 years ago (Leborgne 1955, 1960, 1965; Cook \& Carts 1962) but so far it has received attention mainly from those involved in archaeological prospecting (Colani \& Aitken 1966; Tite \& Mullins 1969; Mullins 1971; Graham \& Scollar 1976): a narrow link exists between the magnetic properties and the history of a soil in which the human activity may have had great influence (fire, metal slag, etc.).

The magnetic susceptibility of a soil or a rock is mainly correlated with the amount of ferrimagnetic oxides and the size of the magnetic grains. Magnetic viscosity, the origin of the EM perturbing effects, is mainly correlated to the size distribution of the magnetic grains. Statistical analysis of the 
shape of the population of grains could be done in the laboratory by the determination of the different hysteresis loop parameters $\left(J_{\mathrm{s}}, J_{\mathrm{rs}}, H_{\mathrm{c}}\right)$, but in general these parameters are determined using strong fields and should not be extrapolated for weak fields like those used in field experiments. Consequently, we have measured in the laboratory, parameters directly related to possible field measurements. This work was originated by Mullins \& Tite (1973). Taking into account the field constraints existing in EM surveying, we adopted the following experimental features:

(1) a highly uniform field is maintained all over the sample volume: this is necessary to have absolute values directly determined from geometrical and electrical parameters, and to have the same field in both frequency and time domain experiments;

(2) a weak field $(50 \mu \mathrm{T})$ is used corresponding to the range for common EM sources;

(3) a wide number of frequencies is used in order to have a good definition of the frequency variations; and

(4) several channels are scanned in order to define precisely the signal decrease after the current cut-off in the time domain.

\section{DESCRIPTION OF THE SAMPLES}

We have studied more than 50 soil samples. Apart from calibration problems and comparison with previously analysed samples, all samples came from sites where we have observed anomalous EM responses.

For the relative calibration check of our device, we have used among other methods, manganese sulphate powder samples $\left(\mathrm{MnSO}_{4}, 4 \mathrm{H}_{2} \mathrm{O}\right)$ of different magnetic susceptibilities corresponding to different weights of the sulphate diluted in a non-magnetic matrix (plaster). A blank test has been performed with the plaster only and the corresponding susceptibility found to be less than $10^{-6}$ SI.

In order to make some comparison with preceding works, we have studied three samples already analysed by Mullins \& Tite (1973): FN11 which is a top soil from a Roman city formed on lava from Vicino volcanic deposit, DR19 which is a pit fill from an Iron age settlement at Dragonby in Lincolnshire (UK) and finally DC33, a pit fill from Iron age hill fort at Dane's camp, Worcestershire (M. S. Tite, personal communication; Mullins 1971; Mullins \& Tite 1973; Tite \& Linnington 1986).

These three samples are the only ones of which we have a precise idea of the magnetic grain composition by previous works (Mullins 1971): DC33 has no evidence of the presence of multidomain grains. Its low value of interaction field suggests that the grains are completely mixed in the soil. Furthermore, the very low value of blocking field is an indication that the stable single domain grains are nearly spherical (diameter greater than $250 \AA$ ). It is also suggested by Mullins that about 10 per cent of the magnetic grains must be stable single domain, the rest being superparamagnetic. Sample DR19 is similar but there is some evidence of multidomain grains (12 per cent stable single domain grains, 6 per cent multidomain grains and the rest superparamagnetic). The magnetic grains are also well dispersed.

Numerous soils contain antropic remains of highly magnetic materials. These could originate either in the presence of fragments of metal (1) or be induced by fire (2) (baked clays, bricks etc.):

(1) We have been involved in the survey of two sites where anomalous EM responses have been encountered. On these two sites medieval metalworking is known to have taken place. The first site includes iron wastes and ore. It is located in Burgundy and has not yet been excavated at this time. More than 20 samples have been collected there from the bedrock (limestone) to the upper layer. The second site is concerned with the casting of silver (Eisenthür, Sainte Marie aux mines, France).

(2) Finally we have studied a high-susceptibility sample coming from a baked clay of an amphora (Roman shipwreck, peninsula of Giens, France).

\section{INSTRUMENTATION AND EXPERIMENTAL PROCEDURES}

\subsection{Geometry design of the primary and secondary fields}

We have built a device for continuous measurement of the frequency. dependence of magnetic susceptibility in the range from $80 \mathrm{~Hz}$ to $10 \mathrm{kHz}$ and another device for time domain measurement.

Both devices include two coils: the primary which is used to induce the field and the secondary to measure the magnetic moment induced in the sample. To reject the external EM noise and to annul the direct coupling between the primary and the secondary coils, the secondary is made of two coils wound in opposite direction. For the frequency domain apparatus, the secondary coil is inside the primary one. In the time domain apparatus both coils are wound on the same tube.

The constraints for the design of the coils are:

(1) search for the highest possible sensitivity;

(2) high ringing frequency well removed from the required frequency range or time constants (which limits the maximum number of turns);

(3) primary field uniform over the sample volume; and

(4) incuding field of the order of $50 \mu \mathrm{T}$.

We have computed the distribution of the longitudinal and radial component of the magnetic field due to various loop associations. Theoretically, the radial component of the field is antissymetric and, if the sample is isotropic, this component has no effect. The longitudinal field is the only effective field and induces the magnetic moment in the sample. By optimizing the position of the loops, we have obtained a highly uniform longitudinal field of less than 1 per cent variation over the whole sample volume $(6 \mathrm{~cm}$ diameter, $11 \mathrm{~cm}$ length). The results of the computations are displayed in Fig. 1 for both primary and secondary coils of the frequency domain apparatus; data are presented in percentage value with an origin equal to the field value at the centre of the coils $(z=0, r=0)$.

This calculation is done in the same way for the time domain device.

\subsection{Electronics}

The primary field for the frequency device is driven through a frequency response analyser which generates a sinusoidal 

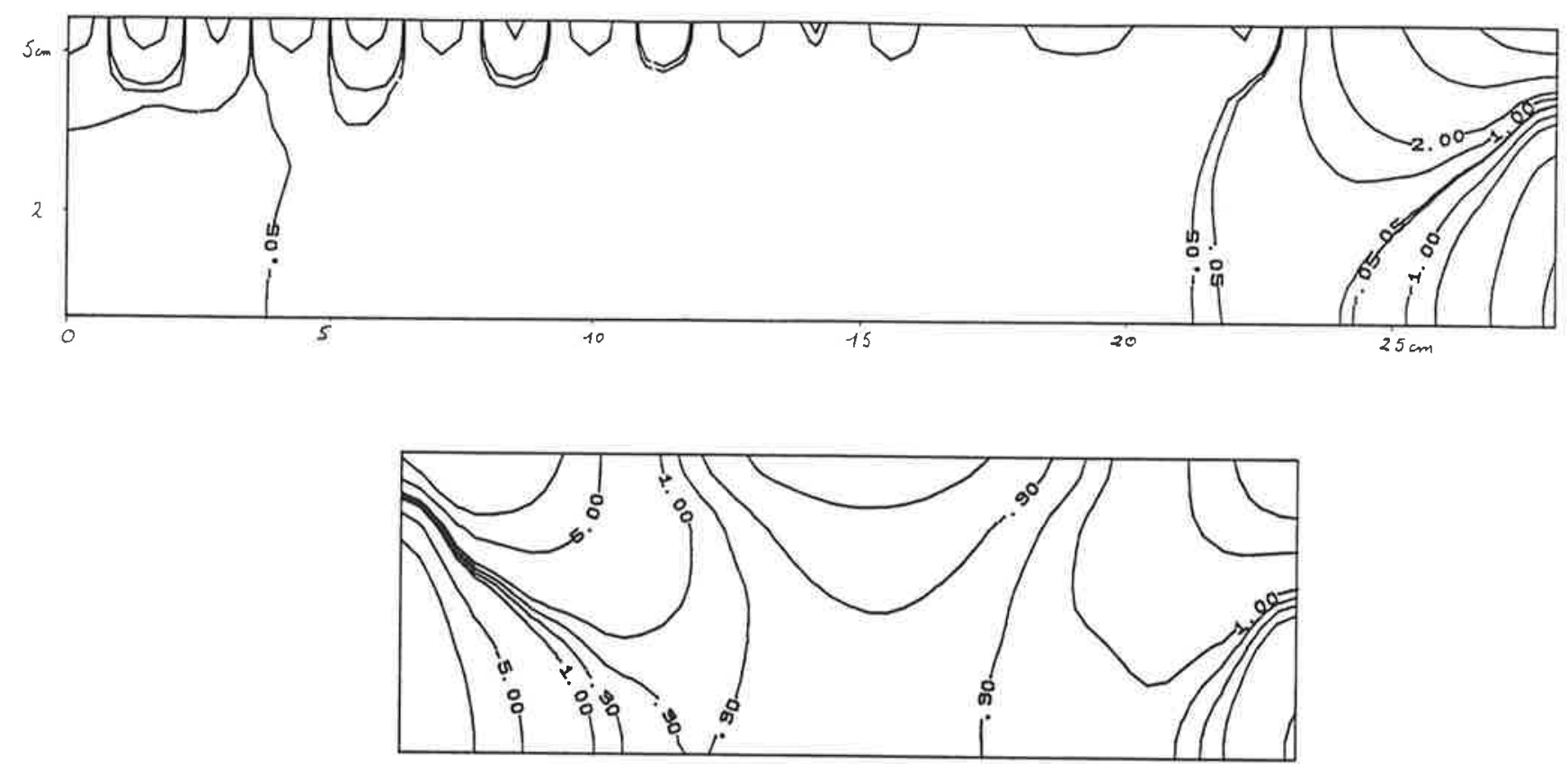

Figure 1. Isovalues of the inducing magnetic field (the isovalues are in per cent with origin taken at the centre of the coil). (a) Primary coil, (b) secondary coil.

Waveform with a known frequency, amplitude and bias. It is also used as a synchronous detector-with stacking and pre-multiplying-for the detection of the current in the secondary coil. This apparatus is monitored by a small computer which performs the task of driving the generator through the sweep sequence, storing and filtering (median filter) the results. A set of 13 frequencies logarithmically spaced between 80 and $10380 \mathrm{~Hz}$ is used. The flow path of the experiment is as follows:

(1) command of the frequency and amplitude of the generator;

(2) manual introduction of the sample into the secondary coil;

(3) stack over a number of cycles (1000);

(4) display and print the in-phase and out-of-phase emf of the secondary coil;

(5) estimation of noise;

(6) removal of the sample and estimation of the zero; and

(7) calculation of the in-phase and out-of-phase susceptibility and an estimation of their standard deviations.

The whole process lasts almost $1 \mathrm{hr}$ per sample (for a stack over 1000 measurements).

The calibration can only be done by using calibrated currents. It has been performed using currents flowing into a precisely designed test coil. Calibration of the primary coil is carried out by using the test coil instead of the sample and recording the voltage due to the coupling with the current flowing in the primary coil. We can demonstrate then that the electrodynamic constant $G_{\mathrm{p}}$ (ratio of the flux $\Phi$ by the moment $M$ ) could be written as

$G_{\mathrm{p}}=\frac{1}{\omega}\left(\frac{e_{\mathrm{bob}}}{e_{\text {prim }}}\right) \frac{R}{n A}$

with a test coil of $n$ turns and surface $A, R$ is the resistor through which we control the current (angular frequency $\omega=2 \pi f)$ in the primary coil $\left(e_{\text {prim }}=R i_{\text {prim }}\right), e_{\text {prim }}$ is the complex emf recorded, and $e_{\text {bob }}$ is the emf through the test coil.

Similarly we use for the calibration of the secondary coil the test coil as a transmitter excited by the signal generator and record the voltage induced in the secondary coil $e_{\text {sec}}$. The electrodynamic constant $G_{\mathrm{s}}$ could be written as

$G_{\mathrm{s}}=\frac{1}{\omega}\left(\frac{e_{\mathrm{sec}}}{e_{\mathrm{bob}}}\right) \frac{R}{n A}$.

The susceptibility could then be derived as follows:

$e_{\mathrm{sec}}=-\frac{d \Phi}{d t}=-G_{\mathrm{s}} \frac{d M}{d t}=-G_{\mathrm{s}} j \omega M=-G_{\mathrm{s}} j \omega K V H_{\mathrm{prim}}$.

The inducing field $H_{\text {prim }}$ could be expressed as

$H_{\text {prim }}=\frac{G_{\mathrm{p}} e_{\text {prim }}}{\mu_{0} R}$

and finally we can derive the susceptibility:

$K=\frac{1}{V} \frac{1}{\omega}\left(\frac{e_{\mathrm{sec}}}{e_{\text {prim }}}\right) \frac{R \mu_{0}}{G_{\mathrm{p}} G_{\mathrm{s}}}$

The complex product $G_{\mathrm{p}} G_{\mathrm{s}}$ is only slightly frequency dependent if we are well removed from the ringing frequency. Nevertheless, we have to measure the real and imaginary part of $\left(G_{\mathrm{p}} G_{\mathrm{s}}\right)$ for the frequencies to be used in the susceptibility measurement. The precision of this calibration depends mainly on the precision of the radius $r$ of the test coil. Its absolute value is estimated around 10.5 per cent (the constant factor in the formula if we use the same resistance for the calibration and the measurements is equal to $\left.n^{2} \pi^{2} r^{4} / R\right)$. $\left(G_{\mathrm{p}} G_{\mathrm{s}}\right)(\omega)$ has been stored in a computer file so that it is possible to calculate in real time both components of $K$ which we will call $K_{\mathrm{p}}$ and $K_{\mathrm{q}}$ respectively for the in-phase and quadrature components. 
All the coils are mechanically decoupled to avoid any changes in their geometry due to the loading of the sample. The temperature must remain as constant as possible: we operate underground in a basement which also avoids a lot of electrical interference.

It is better to use samples of known susceptibility for verification rather than the basis of our calibration. We first used manganese sulphate samples (of mass susceptibility $8.1 \times 10^{-7} \mathrm{~m}^{3} \mathrm{~kg}^{-1}$ ), but if we want to correlate results obtained with surveys in the field the only parameter which makes sense is the volumic susceptibility. So, because of the unknown compaction, the manganese sulphate powder was only used to test the linearity of the response with different amounts of weighted powder. This linearity was found to be better than 0.4 per cent. We have also used a rock sample which has already been analysed with an astatic magnetometer at St Maur des Fossés (Daly, personal communication, sample KD144, November 1986). Its precise remanent and induced magnetizations are known. We are of course only concerned with the induced magnetization. A difference of 2 per cent in the absolute susceptibilities has been found which lies in our experimental errors and in the expected frequency variation.

For the time domain apparatus, special electronic circuitry has been developed which drives a square pulse through the primary coil. When the primary field is switched off, the emf measured in the secondary coil is sampled over six channels. The pulse of current in the primary coil is a square wave of $370 \mu$ s duration, $1 \mathrm{~A}$ amplitude, which corresponds to a field of $50 \mu \mathrm{T}$, and a cut-off time of $2 \mu \mathrm{s}$. Six channels are scanned with a separate amplification for each. These channels are centred at 8.2,14., 24., 45.2, 87.5, 172.2 $\mu \mathrm{s}$ after current cut-off. Calibration has been checked with metallic (i.e. purely conductive) spheres of known radius and conductivity. The laws of decay have been compared with theoretical ones and found to be in good accordance.

\section{THEORY OF FREQUENCY DOMAIN AND TIME DOMAIN MEASUREMENTS}

\subsection{Frequency dependence}

In electromagnetic surveying, several relaxation processes may occur. Depending on the range of frequencies used, different types of relaxation process will predominate. The magnetic fields we measure could be the result of:

(1) displacement currents (dielectric interfaces);

(2) eddy currents (Foucault) induced in conductive parts; and

(3) loss in magnetic materials.

Displacement currents occur with high frequencies where the EM propagation dominates (application of Sub-Surface Radar). For the range of frequencies used in our apparatus $(80 \mathrm{~Hz}-10 \mathrm{kHz})$, only the second types could be measured.

In any type of dispersive medium (Landau \& Lifshitz 1960 ), it is possible to define in terms of complex quantities the three factors: conductivity $\sigma$, dielectric constant $\varepsilon$, and magnetic permeability $\mu$ :

$\mu=\mu^{\prime}-j \mu^{\prime \prime}, \quad \sigma=\sigma^{\prime}-j \sigma^{\prime \prime}, \quad \varepsilon=\varepsilon^{\prime}-j \varepsilon^{\prime \prime}$.

The loss angle is defined as the ratio between the imaginary and the real part of the propagation factor:

$\tan \delta=\frac{\mathscr{I}(k)}{\mathscr{R}(k)}$,

with

$k^{2}=\mu \varepsilon \omega^{2}-j \mu \sigma \omega$.

In order to study the relation between frequency and magnetic susceptibility, we use a distribution (Cole \& Cole 1941) where

$\mu=\mu^{\prime}-j \mu^{\prime \prime}=\mu_{\infty}+\frac{\mu_{\mathrm{s}}-\mu_{\infty}}{1+(j \omega \tau)^{1-\alpha}}$,

with

$\mu_{\infty}=\lim _{\omega \rightarrow \infty}\left(\mu^{\prime}\right), \quad \mu_{\mathrm{s}}=\lim _{\omega \rightarrow 0}\left(\mu^{\prime}\right)$.

$\tau$ is the relaxation time contant such that $\omega \tau=1$ when $\mu^{\prime}=\left(\mu_{\mathrm{s}}+\mu_{\infty}\right) / 2$, and $0 \leq \alpha \leq 1$ is the relaxation parameter where $\alpha=0$ means a Debye relaxation process, and $\alpha=1$ means a continuous spectrum of relaxation times.

In our case the imaginary part $\mu^{\prime \prime}$ is quasi-null, the loss angle is no longer a function of frequency and the time response is a function of $\log (t)$.

This is the case of the classical Néel theory (Neel 1949). This theory is only valid for well-dispersed single domains (SD without interactions). Today, there is no analytical theory for PSD or MD. Néel used Boltzmann statistics for his theory in order to determine the law of distribution of the moments. Recent developments (Moon \& Merrill 1988) use different types of statistics (quasi-equilibrium or non-equilibrium), but the conclusions are not very different except for the determination of $f_{0}$ (maximum possible frequency of reversal) and $E_{\mathrm{a}}$ (activation energy).

Le Borgne (1955) has already shown that the majority of soil magnetic properties originates in the clay fraction, and the magnetic grains must be superparamagnetic, single domain or small multidomain.

We have followed Mullins' demonstration about the frequency dependence of SD but with some modifications (Mullins 1971): let us consider a population of similar magnetic grains characterized by their identical relaxation time $\tau_{0}$. The magnetization $J$ is governed by a Boltzman equilibrium equation:

$\tau_{0} \frac{d J}{d t}+J=J_{\mathrm{s}}$

$J_{\mathrm{s}}$ is a constant whıch varies with the inducing field $h$.

Let $h$ be a harmonic field with magnitude $h_{0}: h=$ $h_{0} \sin (\omega t)$. Then, in the Rayleigh domain, $J_{\mathrm{s}}$ is dependent on $h_{0}$ and varies as $\exp (j \omega t)$ :

$\tau_{0} \frac{d J}{d t}+J=J_{\mathrm{s}}\left(h_{0}\right) \sin (\omega t)$

and

$J=J_{\mathrm{s}}\left(h_{0}\right)\left(\frac{\sin (\omega t)}{1+\omega^{2} \tau_{0}^{2}}-\frac{\omega \tau_{0} \cos (\omega t)}{1+\omega^{2} \tau_{0}^{2}}\right)$.

The first part of this equation is in phase with the applied field $h$ and the second is out of phase ( $\pi / 2 \mathrm{lag})$. 
It is then possible to define the in-phase susceptibility $K_{\mathrm{p}}$ $K_{\mathrm{p}}=\frac{J_{\mathrm{s}}}{h_{0}} \frac{1}{1+\omega^{2} \tau_{0}^{2}}$

and the out-of-phase susceptibility as

$K_{\mathrm{q}}=\frac{J_{\mathrm{s}}}{h_{0}} \frac{\omega \tau_{0}}{1+\omega^{2} \tau_{\mathrm{o}}}$.

If we want to generalize to a population of grains characterized by their relaxation times or their activation energy then

$K_{\mathrm{p}}=\frac{1}{E_{\max }-E_{\min }} \int_{E_{\min }}^{E_{\max }} \frac{J_{\mathrm{s}}(E)}{h_{0}} \frac{1}{1+\omega^{2} \tau^{2}} d E$.

The simplest hypothesis is to admit a uniform spectrum of relaxation times and by consequence of the activation energies: $J_{\mathrm{s}}(E) d E=$ constant $=J_{\mathrm{se}} d E$

$K_{\mathrm{p}}=\frac{\mathrm{J}_{\mathrm{se}}}{h_{0}} \frac{1}{E_{\max }-E_{\min }} \int_{E_{\min }}^{E_{\max }} \frac{1}{1+\omega^{2} \tau^{2}} d E$

$d E=k T d \tau / \tau$ [in Néel theory, it is possible to demonstrate that $1 / \tau$ is proportional to $\exp (-E / k T)]$. With $\tau_{\min }=$ $1 / f_{0} \simeq 10^{-8} \mathrm{~s}$ (minimum time reversal for a magnetic grain estimated with Mossbaüer spectra between $10^{-7}$ and $10^{-9} \mathrm{~s}$ ) it becomes

$K_{\mathrm{p}}=\frac{J_{\mathrm{se}}}{h_{0}} \frac{k T}{k T \ln \left(\tau_{\max } f_{0}\right)} \int_{1 / f_{0}}^{\infty} \frac{d \tau}{\tau\left(1+\omega^{2} \tau^{2}\right)}$

[ $k T \ln \left(\tau_{\max } f_{0}\right)$ has been introduced for normalization and does not exist in Mullins' demonstration]. If $x=\omega \tau$ and $C=\ln \left(\tau_{\max } f_{0}\right)$

$K_{\mathrm{p}}=\frac{J_{\mathrm{se}}}{h_{0} C} \int_{\omega / f_{0}}^{\infty} \frac{d x}{x\left(1+x^{2}\right)}=-\frac{J_{\mathrm{se}}}{h_{0} C} \frac{\ln \left(\omega / f_{0}\right)}{\sqrt{1+\omega^{2} / f_{0}^{2}}}$,

$K_{\mathrm{p}}=\frac{J_{\mathrm{se}}}{h_{0} C} \ln \left(\frac{f_{0}}{\omega}\right) \quad$ if $\omega \ll f_{0}$,

$K_{\mathrm{q}}=\frac{J_{\mathrm{se}}}{h_{0} C} \int_{1 / f_{0}}^{\infty} \frac{\omega}{1+\omega^{2} \tau^{2}} d \tau=\frac{J_{\mathrm{se}}}{h_{0} C}[\operatorname{arctg}(\omega \tau)]_{1 / f_{0}}^{\infty}$,

$K_{\mathrm{q}}=\frac{J_{\mathrm{se}}}{h_{0} C}\left[\frac{\pi}{2}-\operatorname{arctg}\left(\frac{\omega}{f_{0}}\right)\right]$.

If $\omega \ll f_{0}$ then $K_{\mathrm{q}}$ is a constant equal to

$K_{\mathrm{q}}=\frac{J_{\mathrm{se}}}{h_{0} C} \frac{\pi}{2}$.

If we compute the logarithmic derivative of $K_{\mathrm{p}}$ then

$\frac{\partial K_{\mathrm{p}}}{\partial \ln \omega}=\frac{J_{\mathrm{se}}}{h_{0} C} \frac{\partial}{\partial \ln \omega}\left[-\ln \left(\frac{\omega}{f_{0}}\right)\right]=\frac{-J_{\text {se }}}{h_{0} C}=$ constant,

$\frac{2 K_{\mathrm{q}}}{\pi}=\frac{-\partial K_{\mathrm{p}}}{\partial \ln \omega}=\frac{J_{\mathrm{se}}}{h_{0} C}$.

The main conclusions from the above theory are:

(1) a constant out-of-phase susceptibility;

(2) a constant logarithmic derivative of the in-phase susceptibility; and

(3) a direct proportionality between the two latter constants.

\subsection{Link with time domain measurements}

Using the same theory (Mullins 1971) the relation between frequency and time domain is expressed by

$\frac{2 K_{\mathrm{q}}}{\pi}=\frac{1}{h_{0}} \frac{\partial J_{\mathrm{r}}}{\partial \ln t}$

for the viscous remanent magnetization (VRM), $J_{r}$, of the sample. The time domain apparatus we used measures the decay of VRM after a very sharp cut-off of the primary field, the signal is proportional to $-\partial V J_{\mathrm{r}} / \partial \mathrm{t}$. If we suppose that the actual type of law of decay is unknown, we could define the viscosity as a function of time: $S f(t / \tau)$, of which we know only the derivative:

$e=-G_{\mathrm{s}} V S \frac{\partial f\left(h_{0}, t / \tau\right)}{\partial t}$,

$V$ being the volume of the sample, $h_{0}$ the applied field, $G_{\mathrm{s}}$ the electrodynamic constant of the secondary coil and $\tau$ the characteristic relaxation time of the grains.

Looking at the experimental results from Leborgne (1960) for time ranges between 10 and $10^{4} \mathrm{~s}$, the decay law seems to be logarithmic with time. It is then possible to define viscosity as a dimensionless constant equal to

$S=-\frac{1}{h_{0}} \frac{\partial J_{\mathrm{r}}}{\partial \log t}$

The emf could then be written as

$e=-G_{\mathrm{s}} V \frac{\partial J_{\mathrm{r}}}{\partial t}=G_{\mathrm{s}} h_{0} V \frac{S}{t}$

$e t=\left(G_{\mathrm{s}} h_{0} V\right) S$.

A very important fact is that if $S$ is constant then the product (et) should be constant. Further details about the assumption on $S$ and its relation to SD theory will be developed in a forthcoming paper.

Moreover, the assumption of a logarithmic decay of the VRM only stands for an inducing field like a step function. In practice we must take into account the finite length of the inducing field and especially the finite time when the primary field is switched off.

We have developed a simulation taking into account the real shape of the energizing pulse: knowing the response of a single Heaviside function, the response at switching off can be computed as the superposition of a series of Heaviside functions if the field effects are linear. Considering that the induced and remanent viscosity coefficients are equal for a well-dispersed single domain grain population, the response at the rising of the current can also be calculated as a series of Heaviside functions. The two contributions are then substracted.

Let $s(t)$ be the response to a heaveside function and $f(t)$ be the pulse inducing field of duration $T$. The measured emf has been computed as

$\sum_{k=1}^{k=T / \delta T} f(-T+k \delta t)\{s(t+T-k \delta t)-s[t+T-(k-1) \delta t]\}$. 


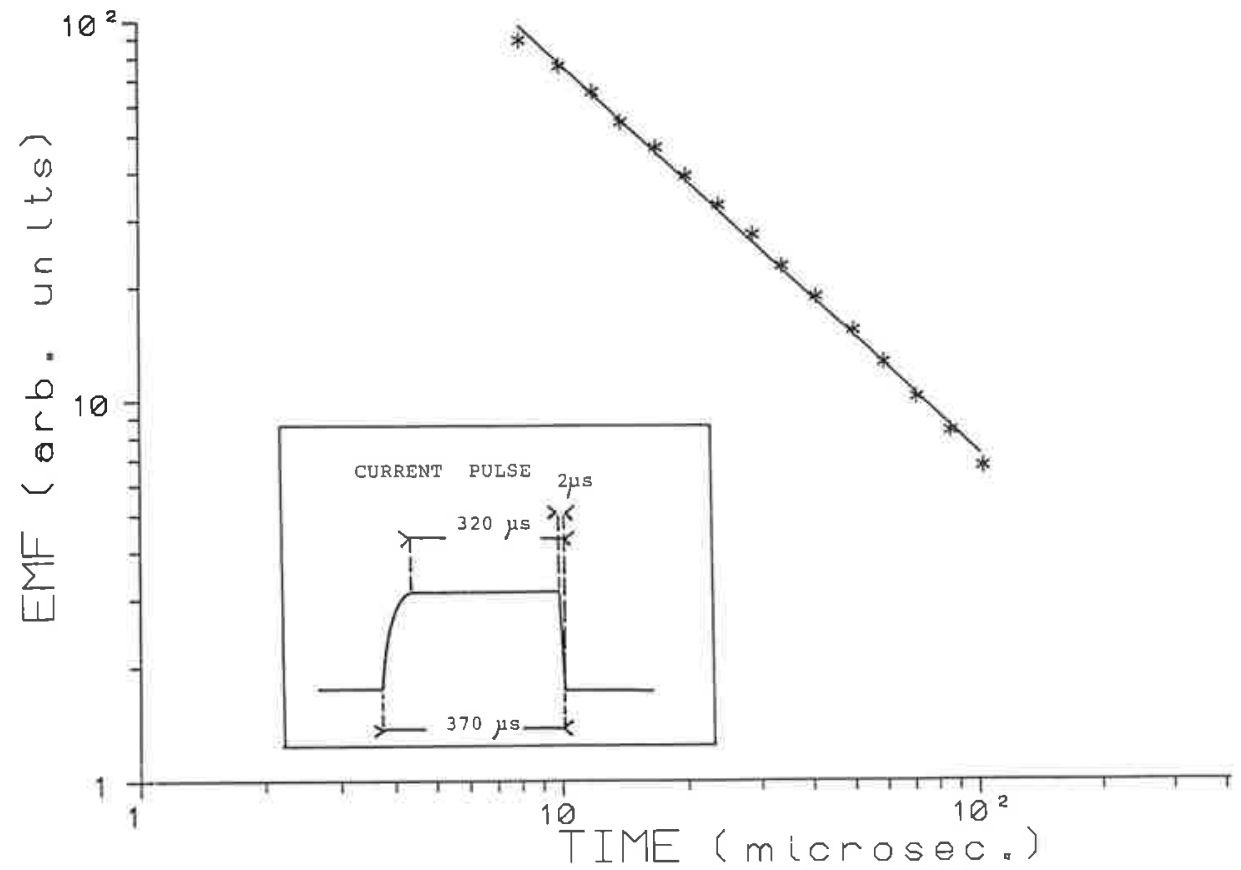

Figure 2. Theoretical relationship with time for a SD grain for the pulse shape shown in the box.

Between 5 and $180 \mu \mathrm{s}$ a best fitting law of power -0.99 (Fig. 2) has been derived taking into account the finite rising time -and decay time of the transmitter pulse. Trials with slightly different pulse shapes and pulse durations exhibit a calculated scatter in the power law ranging from -0.8 to -1.4 .

\section{RESULTS}

In Figs 3 to 6, we represent on the same plot and at the same scale the product of volume $V$ by the in-phase susceptibility (circles) and the quadrature susceptibility (triangles) together with their error bars measured for four different soils (cgs units, volume $V$ of approximatively $160 \mathrm{~cm}^{3}$ ). The horizontal axis is the logarithm of frequency. The first frequency is at $80 \mathrm{~Hz}$. The results for this frequency are the noisiest due to the interferences with $50 \mathrm{~Hz}$. Frequencies are scanned from 80 up to $10380 \mathrm{~Hz}$ by steps of

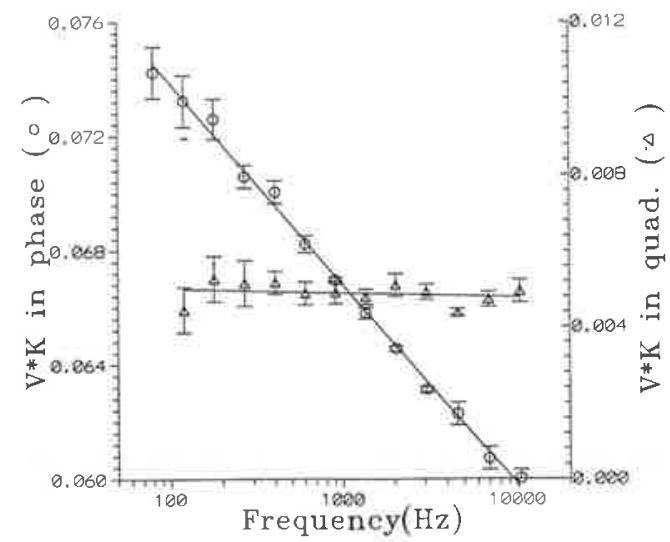

Figure 3. Frequency variations of the in-phase susceptibility (circle) and the quadrature susceptibility (triangles) for sample DC33.
50 per cent. The precision on $K$ is estimated to be of the order of $5.0 \times 10^{-6} \mathrm{emu}\left(6.2 \times 10^{-5} \mathrm{SI}\right)$.

The most common spectrum (I) encountered is displayed in Figs 3 and 4: it is characterized by an in-phase susceptibility which decreases as the logarithm of frequency while the quadrature susceptibility remains nearly constant.

Another spectrum has been observed (II): $K_{\mathrm{q}}$ increases with frequency while $K_{\mathrm{p}}$ decreases slowly until approximately $600 \mathrm{~Hz}$ and then decays very quickly (Fig. 5). When trying to match a type of law for the increase of $K_{\mathrm{q}}$, we have found for all the samples displaying this type of spectrum a power law very near 0.5 .

On two soil samples, we have observed an intermediate spectrum (III): the in-phase susceptibility decreases with frequency as for spectrum I but the quadrature susceptibility increases with the logarithm of frequency (Fig. 6). As we claimed before, except for sample DC33 (Fig. 3) and DR19 (Fig. 6), we do not know the real magnetic composition of

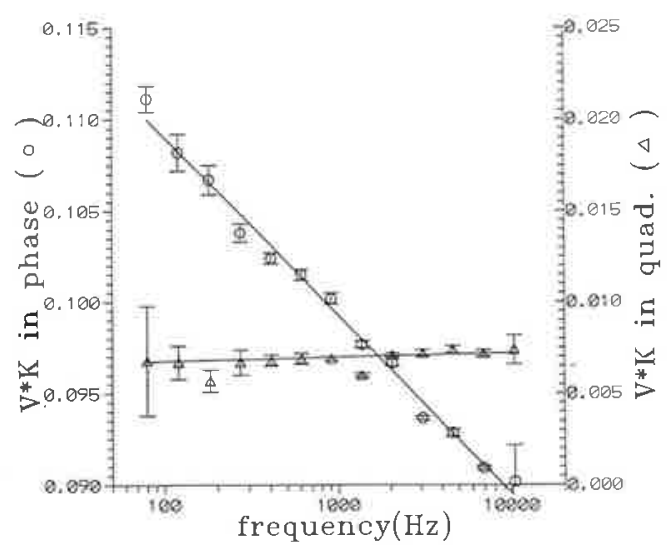

Figure 4. Frequency variations of the in-phase susceptibility (circle) and the quadrature susceptibility (triangles) for sample Ampho. 


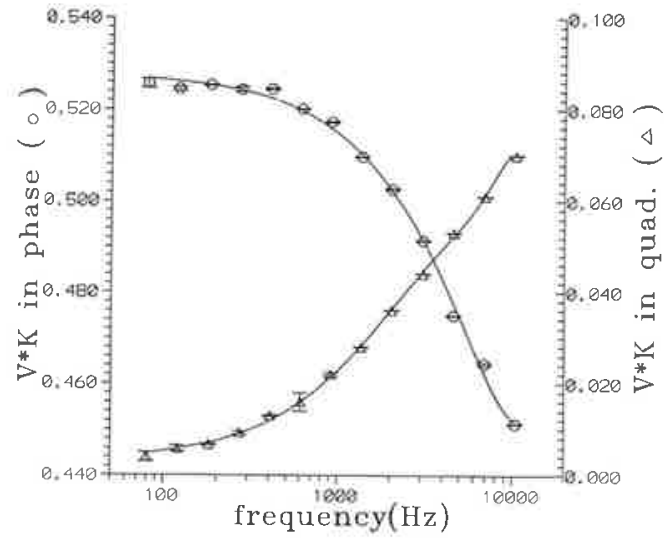

Figure 5. Frequency variations of the in-phase susceptibility (circles) and the quadrature susceptibility (triangles) for sample Minot.

soil samples. As a consequence, we could not argue for a real correspondence between a frequency behaviour and the different parameters of the magnetic population of the soils involved, but some insights could be drawn by comparison with the two samples and the prediction of the SD theory.

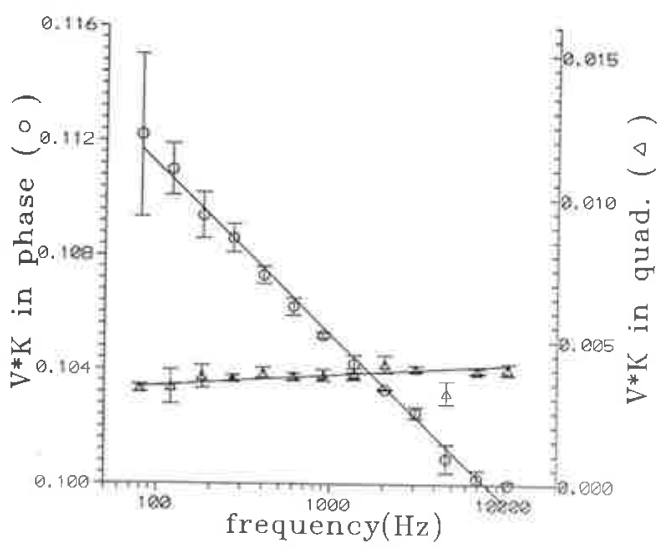

Figure 6. Frequency variations of the in-phase susceptibility (circles) and the quadrature susceptibility (triangles) for sample DR19.

Spectrum $I$ is the most commonly encountered. Many authors (Le Borgne 1955) have already underlined that the magnetic properties of soils come from the grains whose shape is compatible with single domains. We may therefore propose a link between spectrum I and the SD grains. This

Table 1. Values of equation (1) for four selected soil samples.

$\begin{array}{llc}\text { SAMPLE } & \frac{2}{\pi} \mathrm{K}_{\mathrm{q}} & -\frac{\partial \mathrm{K}_{\mathrm{p}}}{\partial \mathrm{Ln} \omega} \\ \text { Amphora } & 34 & 34 \\ \text { DC33 } & 24 & 24 \\ \text { Brevon16 } & 27 & 25 \\ \text { Terre12-18 } & 05 & 04 \\ \text { DR19 } & 16(80 \mathrm{~Hz}) & 20 \\ & \text { to } 20(1 \mathrm{KHz}) & \end{array}$

$$
\text { (1n } 10^{-5} \text { S. I. ) }
$$

hypothesis is confirmed by the magnetic composition of sample DC33 (see Section 2) and by the good accordance with SD theory developed in Section 4.1.

In Table 1 we make the comparison between the two first parts of equation (1) for four selected soil samples which display spectrum I and one sample which displays spectrum II. We can see the very good correlation between the quadrature susceptibility and the rate of decay of the in-phase susceptibility for the first four samples. A small discrepancy only exists for sample DR19. Previous studies have found a 6 per cent multidomain grain component in DR19. We are inclined to think that the small slope of $K_{\mathrm{q}}$ originates in this 6 per cent multidomain grains.

At present, we are unable to make the distinction between the superparamagnetic grains and the single domain grains. The only magnetic particles which should show a quadrature susceptibility are those whose size is compatible with the time used in our experiment $(0.1$ to $10 \mathrm{~ms}$ ). Grains should have their time constant $\tau$ in this range so that they are influenced by the thermal activation. If $\tau$ is greater than the time of the experiment (i.e. operating frequency too high), no effect could be shown. But if $\tau$ is less than the time of the experiment, superparamagnetic effects will predominate. For spectrum II, a theoretical decay could not be derived. Both samples, and others not shown here, seem to have their quadrature susceptibility varying as the square root of the frequency. We have noticed that all these samples contain small metallic particles. Could an explanation be found in the eddy currents induced? Further experiments will be done to check this hypothesis.

Figures 7 to 9 display the first results obtained in the time domain for the following samples: DC33, Amphora and DR19. The logarithm of the emf is plotted against the logarithm of time. We have computed for each sample the slope of the best fitting power law. The majority of the samples studied exhibit surprisingly identical slopes between

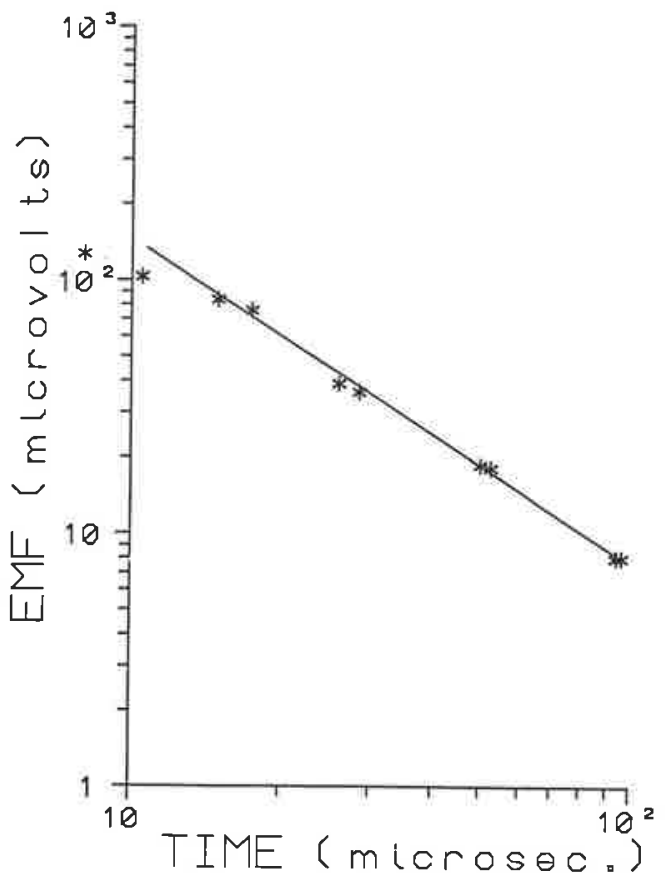

Figure 7. Plot of emf versus time for sample DC33. 


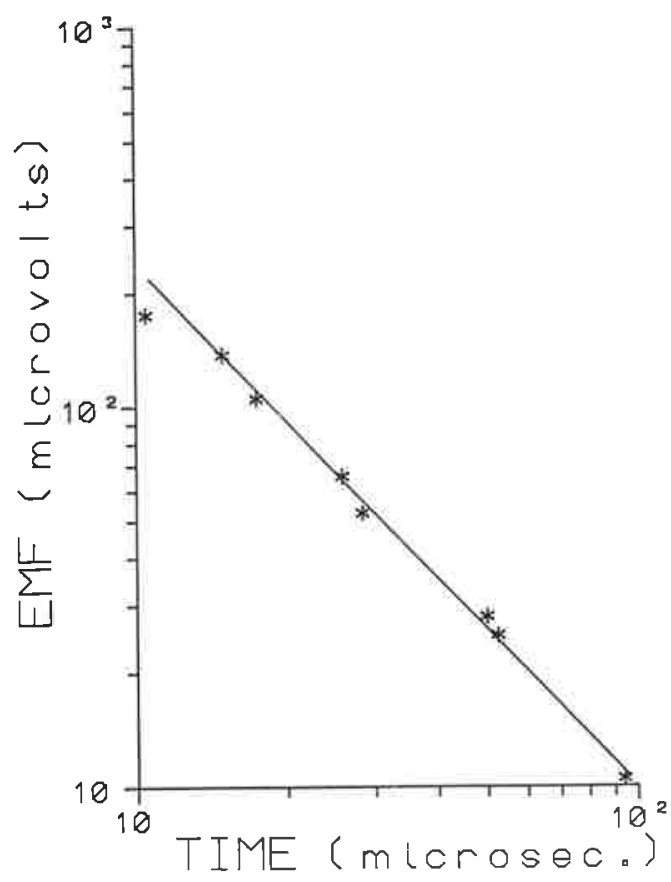

Figure 8. Plot of emf versus time for sample Ampho.

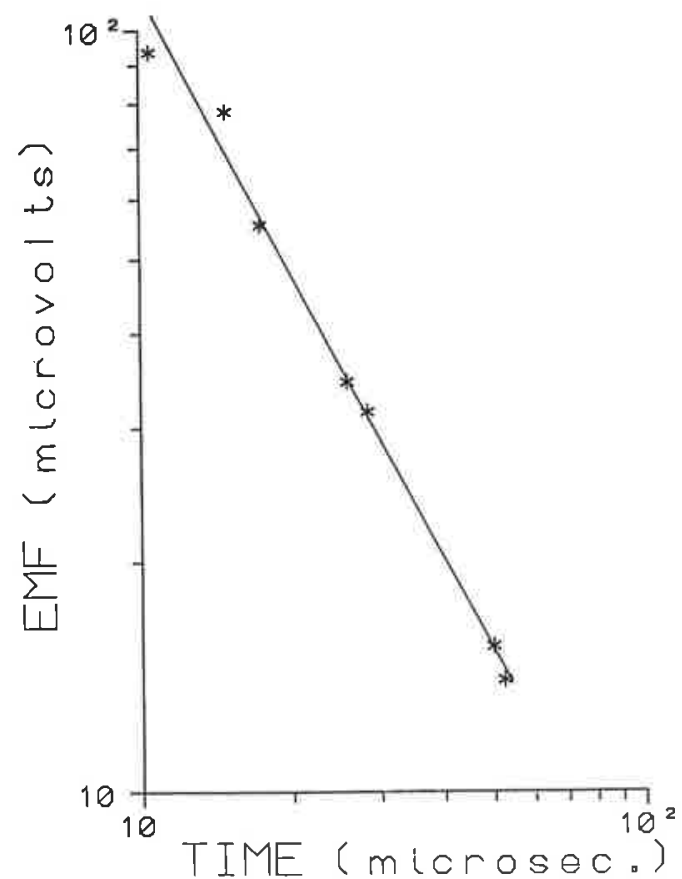

Figure 9. Plot of emf versus time for sample DR19.

Table 2. Coefficients of viscosity for measurement times 20,50 and $100 \mu \mathrm{s}$.

$\begin{array}{lllc}\text { SAMPLE } & \mathrm{S}_{20 \mu \mathrm{s}} & \mathrm{S}_{50 \mu \mathrm{s}} & \mathrm{S}_{100 \mu \mathrm{s}} \\ \text { DC33 } & 65 & 52 & 42 \\ \text { Amphora } & 100 & 65 & 52 \\ \text { DR19 } & 131 & 45 & <10 \\ & & & \left(1 \mathrm{n} 10^{-5} \text { S. . . }\right)\end{array}$

-1.2 and -1.3 . These samples are always those which display the first or third type of spectrum. We could make the hypothesis that this slope is characteristic of SD grains even if this disaccordance with theory is not fully explained (see below).

It is however possible to define an 'instant' value of the coefficient of viscosity for different measurement times, 20 , 50 and $100 \mu \mathrm{s}$, using equation (3), as shown in Table 2. This result is in slight contradiction with the theory developed in Section 4.2 which predicts a power equal to -1 (dependence of the VRM as the inverse of time). But in recent trials and by theory (Dabas 1989; Dabas \& Skinner 1989) we have found slopes between -1.1 and -1.2 when the pulse length is greater $(900 \mu \mathrm{s}$ instead of $370 \mu \mathrm{s})$. Unfortunately, it is not possible with our device to lengthen the inducing pulse over $1 \mathrm{~ms}$. We should also notice that we do not activate exactly the same magnetic population through the two experiments: grains with time constants which span from 10 to $0.1 \mathrm{~ms}$ in the frequency domain are activated compared to 0 to $0.4 \mathrm{~ms}$ in the time domain. This could be an explanation for the slight discrepancy observed. However, we feel confident that the identical derived slopes is the evidence of a similar magnetic composition. Further experiments with pulse length up to $10 \mathrm{~ms}$ will be made.

\section{CONClusions}

The comparison between frequency and time domain results are presented in Table 3. They show a direct relation between $K_{\mathrm{q}}$ and $S$, not exactly conforming to the theoretical value (equation 2) of 1.6, but not far from it, while in the frequency domain equation (1) is correctly verified by 'normal soils' samples. By reconsidering the experimental conditions we have to point out that the samples were the same for measurements in both domains, that the fields are precisely known and uniform over the whole volume, and that the electrodynamic constants and other electrical parameters are well defined. The parameters that may intervene in the relative disagreement between experiment and theory are: the argument of the power law decay (less than -1 and due in part to the duration of the pulse), and the difference in time constants (those taken into account in TD measurements being slightly shorter than those in FD).

Physically $K_{\mathrm{q}}$ and $S$ bring the same information, the grain size distribution characterization of which by measurements in the field will be of high interest for soil and rock studies. It is important to confirm the results presented here by analysing experiments undertaken over a large number of samples (Dabas \& Skinner 1989) and to consider also longer pulse durations and a better correspondence between time constants in both domains.

Table 3. Comparison between frequency and time domain results.

$\begin{array}{llcc}\text { sample } & \mathrm{Kq}_{20} / \mathrm{S}_{20 \mu \mathrm{S}} & \mathrm{Kq} / \mathrm{S}_{50 \mu \mathrm{s}} & \mathrm{Kq} / \mathrm{S}_{100 \mu \mathrm{s}} \\ \text { DC 33 } & 0.5 & 0.6 & 0.7 \\ \text { Amphora } & 0.7 & 0.9 & 1.1 \\ \text { DR 19 } & 0.6 & 0.9 & 1.1\end{array}$




\section{REFERENCES}

Buselli, G., 1982. The effect of nearsurface superparamagnetic material on electromagnetic measurements, Geophysics, 47, 1315-1324.

Colani, C. \& Aitken, M. J., 1966. Utilisation of magnetic viscosity effects in soils for archaeological prospection, Nature, 4, 95-102.

Cole, K. S. \& Cole, R. H., 1941. Dispersion and absorption in dielectrics, J. Chem. Phys., 9, 341.

Cook, J. C. \& Carts, S. L., 1962. Magnetic effects and properties of typical topsoils, J. geophys. Res., 67, 815-828.

Dabas, M., 1989. Comportement magnétique des sols dans le domaine fréquentiel et temporel (VRM). Application à la prospection de sites archéologiques, Thése, Université de Paris VI P. \& M. Curie.

Dabas, M. \& Skinner, J., 1989. Time dependent magnetisation of soils (VRM) and its relationship to quadrature susceptibility, S.E.G. Meeting, Dallas Oct. 1989, Expanded Abstracts, pp. 192-195.

Graham, I. D. G. \& Scollar, I., 1976. Limitations on magnetic prospection in archaeology imposed by soil properties, Archaeophysika, 6, 1-124.

Landau, L. D. \& Lifshitz, E. M., 1960. Electrodynamics of Continuous Media, Pergamon Press, New York.

Leborgne, E., 1955. Susceptibilité magnétique anormale du sol superficiel, Ann. Géophys., 11, 399-419.

Leborgne, E., 1960. Etude experimentale du trainage magnétique dans le cas d'un ensemble de grains magnétiques très fins dispersés dans une substance non magnétique, Ann. Géophys., 16, 445-494.

Leborgne, E., 1965. Les propriétés magnétiques du sol. Application à la prospection des sites archéologiques, Archaeophysika, 1 , 25-36.

Moon, T. \& Merrill, R. T., 1988. Single domain theory of remanent magnetization, J. geophys. Res., 93, 9202-9210.

Mullins, C. E., 1971. The magnetic properties of soils and their application to archaeological prospecting, $P h D$ thesis, University of Essex (published in Archaeophysika, 5, 143-347, 1974).

Mullins, C. E. \& Tite, M. S., 1973. Magnetic viscosity, quadrature susceptibility and frequency dependence of susceptibility in single domain assemblics of magnetite and maghemite, $J$. geophys. Res., 78, 804-809.

Néel, L., 1949. Théorie du trainage magnétique des ferromagnétiques en grains fins avec application aux terres cuites, Ann. Geophys., 5, 99-136.

Tabbagh, A., 1986. Applications and advantages of the Slingram electromagnetic method for archaelogical prospecting, Geophysics, 51, 576-584.

Tite, M. S. \& Mullins, C. E., 1969. Electromagnetic prospecting, a preliminary investigation, Prospezioni Archeologische, 4, 95-102.

Tite, M. S. \& Linnington, R. E., 1986. The magnetic susceptibility of soils from central and southern Italy, Prospezioni Archeologiche, 10, 20-36. 
